\title{
ИНВЕСТИЦИОННЫЕ РЕШЕНИЯ В МОЛОЧНОЙ ОТРАСЛИ АПК В УСЛОВИЯХ РИСКА ПАНДЕМИИ
}

\author{
(c) 2021 Капустина Надежда Валерьевна \\ доктор экономических наук, доцент, \\ профессор департамента экономической безопасности и управления рисками \\ Финансовый университет при Правительстве Российской Федерации, Россия, Москва \\ E-mail: kuzminova_n@mail.ru
}

\section{(c) 2021 Аничкина Ольга Александровна}

кандидат экономических наук, доцент кафедры оценки бизнеса, учета и корпоративных финансов Московский государственный университет технологий и управления им. К. Г. Разумовского (Первый казачий университет), Россия, Москва

E-mail: f-1980@yandex.ru:

\section{(C) 2021 Попов Владислав Русланович}

аспирант кафедры экономики городского хозяйства и сферы обслуживания Московский университет имени С. Ю. Витте, Россия, Москва

E-mail: e-mail: popovlad17@mail.ru

\section{(C) 2021 Арефьев Игорь Игоревич}

магистрант 1 курса кафедры оценки бизнеса, учета и корпоративных финансов Московский государственный университет технологий и управления им. К. Г. Разумовского (Первый казачий университет), Россия, Москва

E-mail:igarefa25@yandex.ru

В данной статье рассматриваются возможности инновационно-инвестиционных решений в молочной отрасли АПК, а также рассматривается их эффективность. В качестве основного инвестиционного решения в процессе исследования было выбрано внедрение в производство йогурта концентрата сывороточных белков. Способ получения нового вида йогурта экономически эффективен для исследуемой отрасли. Актуальность данного исследования заключается в том, что эффективное использование инвестиций имеет важное значение для развития предприятий. Активный инвестиционный процесс ведет к эффективности производства, стабильному экономическому росту, способствует повышению жизненного уровня населения и предопределяет экономический потенциал страны.

Ключевые слова: молочная отрасль, инновационно-инвестиционные решения, АПК, риск пандемии, эффективность.

Роль инвестиционных решений в динамичном развитии, функционировании и поддержании определенного уровня экономики страны огромна и значима, особенно в условиях риска пандемии. В современных рыночных условиях конкурентной борьбы, предприятию необходимо постоянно развиваться и совершенствоваться. Следовательно, возникает необходимость в инвестициях. Инвестиции позволяют предприятиям получить возможность расширять и модернизировать производство, улучшать качество выпускаемой продукции, увеличивать рынки сбыта продукции, тем самым повышать конкурентоспособность.
В условиях рынка и реализации множества новых факторов риска инвестиционные проекты необходимы всем: потребителям-инвесторам, кредиторам и самому предпринимателю, которые должны тщательно анализировать поставленные цели, проверить их реалистичность. Инвестиционные решения являются одним из ведущих факторов развития и увеличения рыночной стоимости организации.

Актуальность данного исследования заключается в том, что правильное принятие инновационно-инвестиционных решений имеет важное значение для развития и повышения экономической эффективности деятельности 
предприятий. Эффективные инвестиционные решения приводят к росту эффективности производственных и иных процессов в организации и обществе, проявляющихся в стабильном экономическом росте, в повышении жизненного уровня населения и формирует экономический потенциал как на региональном, так и на мировом уровне.

Для наиболее эффективного использования инвестиционно-финансовых ресурсов предприятие предлагает свой вариант использования инвестиций, который отражается в бизнес-плане инвестиционного проекта, который представляет собой общее руководство действий для принятия решений по инвестированию финансовых ресурсов предприятия. Именно с помощью бизнес-плана инвестиционного проекта предприятие планирует возможные достижения долгосрочных тенденций экономического развития и адаптации к ним.

Являясь неотъемлемой частью современного (рыночного) механизма хозяйствования, инвестиции, помимо капитализации (вовлечения в оборот дополнительных ресурсов) и тем самым обеспечения устойчивости экономического роста, выполняют свойственные им функции. К основным функциям относятся: регулирующая; распределительная; стимулирующая; индикативная [2].

Регулирующая функция. Инвестиции являются инструментом, оказывающим корректирующее воздействие на процессы воспроизводства капитала и поддерживающим темпы его роста, способствующим структурной перестройке экономики в соответствии с требованиями времени, опережающему развитию наиболее важных ключевых (прорывных) отраслей хозяйства, ускорению научно-технического прогресса, повышению социального благосостояния [1].

Распределительная функция. Посредством инвестирования осуществляется распределение созданного общественного продукта в его денежной форме между отдельными субъектами, уровнями и сферами общественного производства и видами деятельности [1].

Стимулирующая функция [1]. Отсутствие инвестиций, их нерегулируемый отток ведут, как правило, сначала к рецессии (спаду производства), затем к стагнации (длительному застою экономики). Наличие инвестиций, их приток, напротив, способствуют оживлению деловой активности, научному, техническому и иному созидательному творчеству, развитию предпринимательской инициативы. Ничто не возникает из ничего. Отсюда вытекает аксиома экономики (положение, не требующее доказательства): вложил - получил. Поэтому инвестиции - это открывающаяся возможность реализации как ближайших, так и далеко идущих планов достижения поставленных целей. Резюмируя, инвестирование можно охарактеризовать как путь к стратегическому успеху [1].

Индикативная функция, понимаемая как способность инвестиций посредством меняющейся активности указывать, ориентировать, рекомендовать, позволяет отслеживать (контролировать) движение к поставленной цели и вырабатывать такие регулирующие механизмы и инструменты, которые обеспечивают, как минимум, равновесное, а потому стабильное состояние социально-экономической системы страны, каждого ее региона, экономики отдельно взятого предприятия [1].

На основе этой идеи был разработан инвестиционный проект, который, на наш взгляд, является продуктивным и экономически эффективным, так как полученный диетический йогурт будет являться привлекательным не только для потребителей, но и для производителей. Это связано с тенденцией стремления производителей расширить ассортимент продукции, предлагая всё новые разновидности и оттенки вкусов йогуртов.

Проблематика исследования заключается в том, что молочную сыворотку неправильно используют. По данным аналитической статистики «Milknews», в России используется только 20\% молочной сыворотки. Остальное сливается, причем сливы наносят большой вред экологии. Именно поэтому надо разработать правильный инвестиционный проект, который поможет снизить вред земле и повысить использование молочной сыворотки в качестве полезного продукта.

В современных рыночных условиях конкурентной борьбы, предприятию необходимо постоянно развиваться и совершенствоваться. Следовательно, возникает необходимость в инвестициях.

Инвестиции позволяют предприятиям улучшать качество выпускаемой продукции, увеличивать рынки сбыта продукции, тем самым повышать конкурентоспособность. В условиях рынка инвестиционные проекты необходимы всем: потребителям - инвесторам, кредиторам 
и самому предпринимателю, которое должно тщательно анализировать поставленные цели, проверить их реалистичность. Инвестиционные решения являются одним из ведущих факторов развития и увеличения рыночной стоимости организации.

Эффективное использование инвестиций имеет важное значение для развития предприятий. Активный инвестиционный процесс ведет к эффективности производства, стабильному экономическому росту, способствует повышению жизненного уровня населения и предопределяет экономический потенциал страны.

Пищевая промышленность является неисчерпаемым потенциалом для возможности эффективного вложения финансовый ресурсов.

Объем производства сыворотки напрямую зависит от молочного производства, следовательно, необходимо рассмотреть данный рынок.

Молочная сыворотка - это субстанция или жидкость, которая является остаточным явлением после сворачивания и процеживания молока.
Сыворотка - побочный продукт который используется при производстве большого колличества сыров, творога, пищевого и технического казеина [3].

В таблице 2 представлена ситуация пандемии и ее влияние на молокоперерабатывающем производстве.

В сырьевом секторе наблюдалась положительная динамика, по итогам достаточно сложного года пандемии прирост товарного молока составил 3,8\%.

По данным Росстата объем промышленного производства молока, кроме сырого в январеавгусте 2020 года составил 3583,5 тыс.т. (на 0,7\% выше аналогичного периода 2019 года), продуктов кисломолочных (кроме творога) - 1886,9 тыс.т. (-0,9\%), сыров - 376,5 тыс.т. (+6,5\%), молоко-содержащих продуктов с заменителем молочного жира, произведенных по технологии сыра - 126,7 тыс.т. (+6,6\%), масла сливочного 195,1 тыс.т. (+7,5\% больше), молока и сливок сухих $-113,2$ тыс.т. (+2,3\%).

Таблица 1. Реализуемые проекты по переработке молочной сыворотки [4]

\begin{tabular}{|c|c|c|c|c|}
\hline Холдинг & Завод & $\begin{array}{l}\text { Мощность, } \\
\text { тыс. т в год }\end{array}$ & Конечный продукт & Потребленне \\
\hline $\begin{array}{l}\text { «Вимм-Бнлль- } \\
\text { Данн» }\end{array}$ & Рубцовский завод & 9,6 & Сухая сыворотка & $\begin{array}{l}\text { Внутри } \\
\text { холдинга }\end{array}$ \\
\hline $\begin{array}{l}\text { «Вимм-Бнлль- } \\
\text { Данн» }\end{array}$ & $\begin{array}{c}\text { Лнанозовский } \\
\text { завод } \\
\end{array}$ & 4,3 & $\begin{array}{c}\text { Деминерализованная } \\
\text { сыворотка }\end{array}$ & $\begin{array}{l}\text { Внутри } \\
\text { холдинга }\end{array}$ \\
\hline \multirow[t]{2}{*}{ «Молвест» } & $\begin{array}{c}\text { MK } \\
\langle\text { «Воронежский }\rangle\end{array}$ & 24 & $\begin{array}{c}\text { Деминерализованная } \\
\text { сыворотка }\end{array}$ & $\begin{array}{l}\text { Внутри } \\
\text { холдинга }\end{array}$ \\
\hline & AO «Сыродел» & 2,5 & Сухая сыворотка & $\begin{array}{l}\text { Внешним } \\
\text { клиентам }\end{array}$ \\
\hline
\end{tabular}

Таблица 2. Влияние пандемии на молокоперерабатывающем производстве [5] (по данным МСР, Росстат, ФТС РФ)

\begin{tabular}{|l|c|c|c|c|}
\hline \multicolumn{1}{|c|}{ Продукт } & $\mathbf{2 0 1 9}$ & $\mathbf{2 0 2 0}$ & $\begin{array}{c}\mathbf{2 0 2 0} \text { год } \\
\text { к 2019, \% }\end{array}$ & + + - \\
\hline Питьевое молоко, млн.т. & 5,3 & 5,4 & 2,0 & \\
\hline Сливки, тыс.т. (2018-2020 рост) & 162,8 & 187,6 & 13,2 & \\
\hline Кисломолочная (кр.творога), млн.т. & 2,76 & 2,75 & 0,4 & \\
\hline Сметана, тыс.т. (2019-2020 рост) & 514,7 & 532,0 & 3,4 & \\
\hline Сыр, тыс.т. (2017-2020 рост) & 524,0 & 566,1 & 8,0 & \\
\hline Молокосодержащ.(по технологии сыра), тыс.т. & 174,0 & 192,2 & 10,0 & \\
\hline Сливочное масло, тыс.т. & 260,2 & 282,0 & 8,3 & \\
\hline
\end{tabular}


В следующем году по прогнозам экспертов сектор товарного молока даст прирост в 3,0\%, что является максимально положительной динамикой.

Перерабатывающий сектор сохранил свои позиции в течении всего 2020 года на фоне раста потребительского спроса на отечественные товары, что наглядно видно на рисунке 1.

Ценность молочной сыворотки и перспек- тивы ее использования в молочной промышленности доказана и неоспорима. Качественное функционирование молочной промышленности России требует повышения эффективности производства. В первую очередь, это касается ресурсосбережения, так как затраты на сырье составляют $80 \%$ себестоимости молочных продуктов.

Идея добавления концентрата сывороточных белков в йогурт является, на наш взгляд,

Таблица 3. Промышленного производства молока [5] (по данным МСР, Росстат, ФТС РФ)

\begin{tabular}{|c|c|c|c|}
\hline \multicolumn{4}{|l|}{ Производственные показатели } \\
\hline январь-авгүст & 2019r. & 2020r. & $\%$ \\
\hline Валовый надой молока, тыс.тн (в сельхоз. организациях) & 11420,9 & 12105,9 & 106,0 \\
\hline Поголовье коров на конец отчетного периода, тыс. голов (в сельхоз. организациях) & 3257,2 & 3276,0 & 100,6 \\
\hline \multicolumn{4}{|l|}{ Перерабатывающая промышленность-производство, тыс.тн } \\
\hline январь-авгүст & 2019r. & 2020r. & $\%$ \\
\hline Молоко, кроме сырого & 3557,1 & 3583,5 & 100,7 \\
\hline Продукты кисломолочные (кроме творога и продуктов из творога) & 1903,9 & 1886,9 & 99,1 \\
\hline Сыры & 353,6 & 376,5 & 106,5 \\
\hline Молокосодержащие продукты с заменителем молочного жира, произведенные по технологии сыра & 118,9 & 126,7 & 106,6 \\
\hline Масло сливочное & 181,5 & 195,1 & 107,5 \\
\hline Молоко и сливки сухие, сублимированные & 110,7 & 113,2 & 102,3 \\
\hline
\end{tabular}
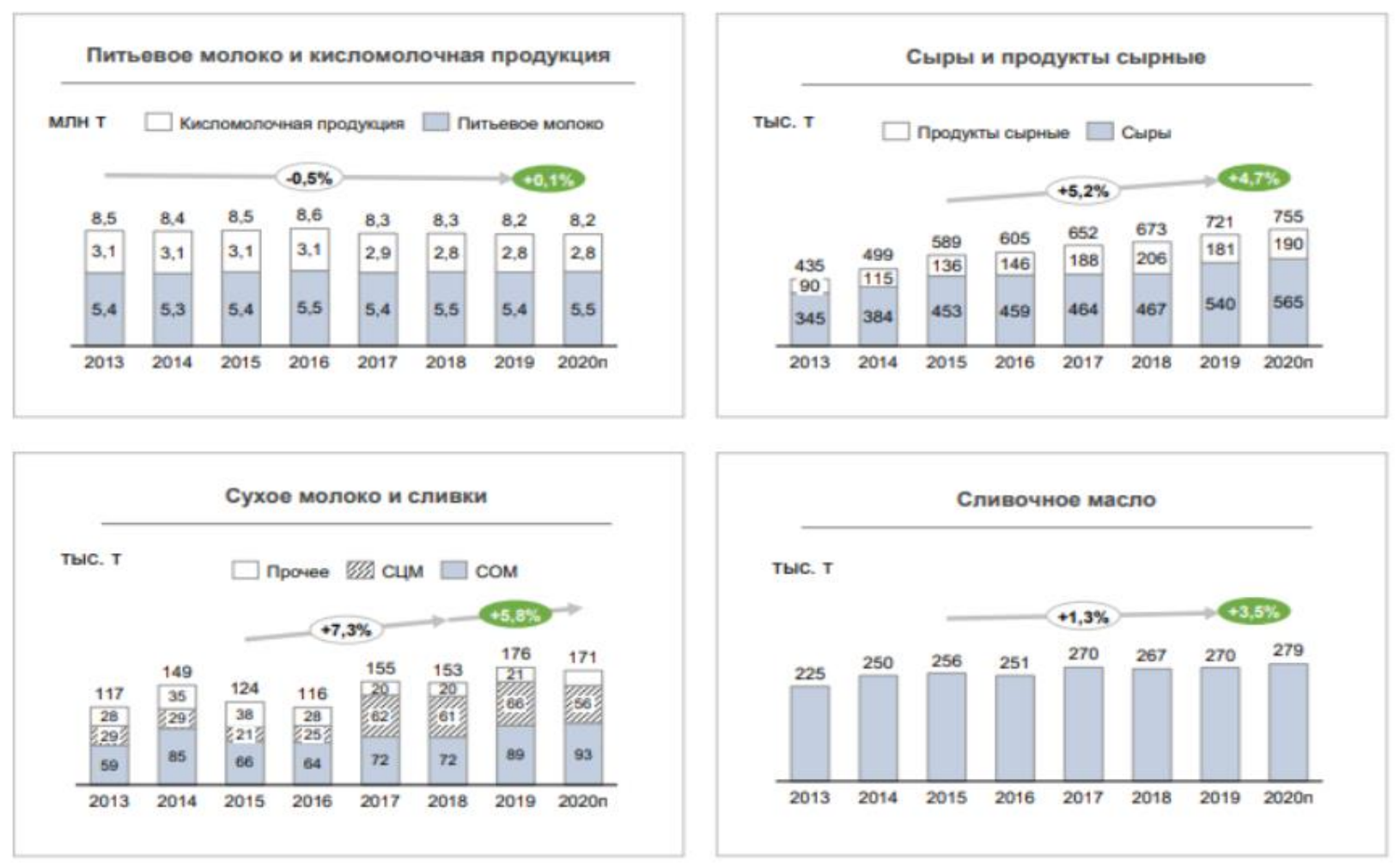

Puc. 1. Переработка молока [6] (по данным аналитической статистики «Milknews») 
продуктивной и экономически эффективной, так как полученный диетический йогурт будет инвестиционно привлекательным.

В ходе проведенных финансовых расчетов установлено, что: срок окупаемости типово- го проекта составит 5 месяцев, рентабельность продаж составит 35,16\%, экономическая эффективность - 62,73\%. Проект стоит принять как возможность инвестирования с минимальными рисками.

\section{Библиографический список}

1. Анализ инвестиционных проектов: учеб. пособие / Н. Ю. Ковалевская. - Иркутск: Изд-во БГУ, 2018. -25 с.

2. Инвестиции. Учебник для вузов. Под ред. Л.И.Юзвович, С.А.Дегтярева, Е.Г. Князевой. 2-е изд., испр. и доп.-Екатеринбург: Изд-во Урал. ун-та, 2018. - 59 с.

3. Объемы российского производства молочной сыворотки в 2018 году // [Электронный ресурс] URL: https:// alto-group.ru/new/961-obemy-rossiyskogo-proizvodstva-molochnoy-syvorotki-v-2017-godu-uvelichilis-na-7. html (дата обращения: 07.05.2021)

4. 10 графиков о состоянии рынка молочной сыворотки // [Электронный ресурс] URL: https://milknews.ru/ analitika-rinka-moloka/rinok-moloka-v-Rossii/grafiki-syvorotka-rf.html (дата обращения: 07.05.2021)

5. Федеральная служба государственной статистики // [Электронный ресурс] URL: https://rosstat.gov.ru/ (дата обращения: 07.05.2021)

6. «Milknews» новости и аналитика молочного рынка https://milknews.ru/longridy/molochniy-rynok-rossiy-2020. html (дата обращения: 07.05.2021) 